This item was submitted to Loughborough's Research Repository by the author.

Items in Figshare are protected by copyright, with all rights reserved, unless otherwise indicated.

\title{
A single session of resistance exercise does not reduce postprandial lipaemia
}

PLEASE CITE THE PUBLISHED VERSION

PUBLISHER

(C) Taylor and Francis

LICENCE

CC BY-NC-ND 4.0

REPOSITORY RECORD

Burns, Stephen F., Heather Corrie, Ester Holder, Thomas Nightingale, and David J. Stensel. 2019. "A Single Session of Resistance Exercise Does Not Reduce Postprandial Lipaemia". figshare.

https://hdl.handle.net/2134/2210. 
This item was submitted to Loughborough's Institutional Repository by the author and is made available under the following Creative Commons Licence conditions.

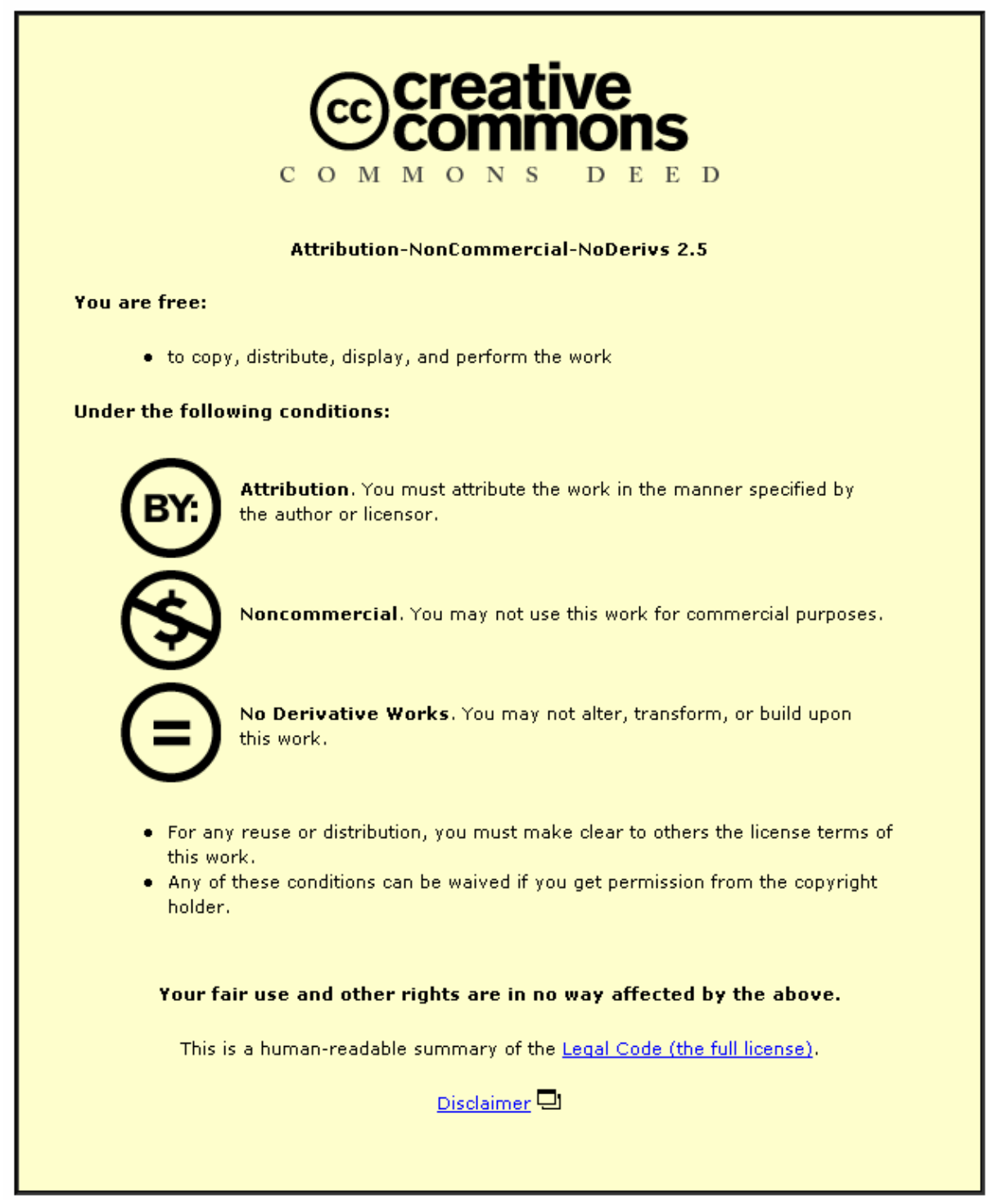

For the full text of this licence, please go to: http://creativecommons.org/licenses/by-nc-nd/2.5/ 


\section{ㄴoughborough University}

A single session of resistance exercise does not reduce postprandial lipaemia

Stephen F Burns, Heather Corrie, Ester Holder, Thomas Nightingale and David J

Stensel

School of Sport and Exercise Sciences

Loughborough University

Loughborough

Leicestershire

LE11 3TU, UK

Abbreviated title: Resistance exercise and postprandial lipaemia

\section{Correspondence and requests for reprints:}

Dr David Stensel

School of Sport and Exercise Sciences

Loughborough University

Loughborough, Leicestershire

LE11 3TU, UK

Phone: $\quad$ +44 (0)1509 226344

Fax: $\quad$ +44 (0)1509226301

E-mail: $\quad$ d.j.stensel@lboro.ac.uk 
Key Words: triacylglycerol, weight lifting, energy expenditure, substrate oxidation 
A single session of resistance exercise does not reduce postprandial lipaemia

Abbreviated title: Resistance exercise and postprandial lipaemia

Key Words: triacylglycerol, weight lifting, energy expenditure, substrate oxidation 


\section{ABSTRACT}

2 This study investigated the effect of a single session of resistance exercise on

3 postprandial lipaemia. Eleven healthy, normolipidaemic men aged 23 (SE 1.4) years

4 performed two trials at least one-week apart in a counterbalanced randomized

5 design. In each trial participants consumed a test meal (1.2g fat, $1.1 \mathrm{~g}$ carbohydrate,

$6 \quad 0.2 \mathrm{~g}$ protein and $68 \mathrm{~kJ}$ per $\mathrm{kg}$ body mass) between 08.00 and 09.00 following a 12

7 hour fast. The afternoon before one trial participants performed an 88 minute bout of

8 resistance exercise. Prior to the other trial participants were inactive (control trial).

9 Resistance exercise was performed using free weights and included 4 sets of 10repetitions of each of 11 exercises. Sets were performed at $80 \%$ of 10 repetition maximum with a 2 minute work and rest interval. Venous blood samples were obtained in the fasted state and at intervals for $6 \mathrm{~h}$ postprandially. Fasting plasma triacylglycerol (TAG) concentration did not differ significantly between control and exercise trials (mean $\pm \mathrm{SE}: 1.03 \pm 0.13 \mathrm{mmol} \cdot \mathrm{L}^{-1}$ versus $0.94 \pm 0.09 \mathrm{mmol} \cdot \mathrm{L}^{-1}$; respectively). Similarly the $6 \mathrm{~h}$ total area under the plasma TAG concentration versus time curve did not differ significantly between control and exercise trials $\left(9.84 \pm 1.40 \mathrm{mmol} \cdot \mathrm{L}^{-1} \cdot 6 \mathrm{~h}\right.$ versus $9.38 \pm 1.12 \mathrm{mmol} \cdot \mathrm{L}^{-1} \cdot 6 \mathrm{~h}$; respectively). These findings suggest that a single session of resistance exercise does not reduce postprandial lipaemia. 


\section{INTRODUCTION}

Elevated postprandial triacylglycerol (TAG) concentrations are independently associated with coronary artery disease (Patsch et al., 1992). Several mechanisms have been proposed to explain this association. Increased postprandial TAG concentrations may promote atherosclerosis due to multiple disturbances in lipoprotein metabolism which encourage: a) an accumulation of triglyceride rich lipoprotein remnants in the plasma; b) catabolism of high density lipoproteins; c) formation of small, dense low density lipoproteins which have an increased susceptibility to oxidation (Cohn, 1998; Karpe and Hamsten, 1995). Interventions that reduce postprandial TAG concentrations may therefore reduce the development of atherosclerosis.

Many studies have shown that a single bout of aerobic exercise reduces postprandial lipaemia (Aldred et al., 1994; Tsetsonis and Hardman, 1996a; Tsetsonis and Hardman, 1996b; Tsetsonis et al., 1997; Gill et al., 2003). This reduction appears to be transient, however, since detraining leads to a prompt elevation in postprandial lipaemia (Hardman et al., 1998; Herd et al., 1998). Thus, exercise must be performed frequently for continued benefit. Two mechanisms have been proposed to explain the TAG-lowering effects of aerobic exercise. One is an increase in lipoprotein lipase (LPL) activity which may enhance the uptake of TAG into previously exercised muscle (Seip and Semenkovich, 1998). The other is a reduced rate of secretion of hepatic very low density lipoproteins (Gill et al., 2001; Malkova et al., 2000). Furthermore, energy expenditure during exercise appears to be the 
primary determinant of the exercise-induced reduction in postprandial lipaemia (Gill et al., 2002; Petitt and Cureton, 2003; Tsetsonis and Hardman, 1996b).

Although many studies have addressed the effects of aerobic exercise on postprandial lipaemia, to our knowledge only one study has examined the influence of resistance exercise on postprandial lipaemia (Petitt et al., 2003). This study found that postprandial lipaemia was decreased following resistance exercise in comparison to a control trial. This is surprising because the estimated energy expenditure during the resistance exercise was only 1.7 MJ. This is at the lower end of the range of values reported in studies of aerobic exercise and postprandial lipaemia (1.5 to 7.2 MJ) (Petitt and Cureton, 2003).

Given that most longitudinal studies have not found changes in TAG concentration following resistance training (Durstine and Haskell, 1994), this recent finding of lowered postprandial lipaemia following a single session of resistance exercise requires confirmation. Therefore, the present study sought to examine the influence of resistance exercise on postprandial lipaemia in a group of young adult males. Specifically, we sought to evaluate the hypothesis that a single session of resistance exercise would lower postprandial lipaemia providing that the energy expenditure was sufficient. 


\section{METHODS}

Participants.

Eleven male volunteers aged 18-40 participated in the study which was approved by the University's Ethical Advisory Committee. The participants gave written informed consent after receiving an explanation of the procedures and risks involved. Participants were recruited only if they met the following criteria: nonsmoking, no known history of cardiovascular disease, resting arterial blood pressure $<160 / 95 \mathrm{~mm} \mathrm{Hg}$, not taking any medication known to affect lipid or carbohydrate metabolism. Some physical characteristics of the participants are shown in Table 1. Most participants reported that they were involved in some form of recreational physical activity but none of them performed resistance exercise on a regular basis.

\section{TABLE 1 NEAR HERE}

\section{Study design.}

Prior to the main trials participants visited the laboratory twice. During the first visit anthropometric data were collected and participants performed 10-repetition maximum tests for each of the 11 resistance exercises employed in the study. The 10-repetition maximum values were determined by trial and error by adding/removing weights after each attempt as required (this applied to all exercises including sit ups). Participants were allowed to take as long as they felt necessary to recover from each attempt. The order in which the 10-repetition maximum tests were performed was the same for each participant i.e. dead lift, bench press, upright row, squat, shoulder press, bent-over row, lunges, barbell pullover, bicep curls, 
triceps press and sit ups. On the second visit participants completed a practice weight-lifting session. The purpose of this practice session was to ensure that each participant was able to complete the entire exercise session and also to confirm that the weights lifted were producing fatigue from overload by the end of the session. This was confirmed by visual inspection and by verbal feedback from participants.

Following the preliminary visits participants undertook two fat tolerance tests. The first of these tests was performed a minimum of one-week after the practice weight lifting-session. The interval between the two fat tolerance tests was at least oneweek. The afternoon prior to one of the fat tolerance tests participants performed an 88 minute bout of resistance exercise starting at approximately $16.00 \mathrm{~h}$ (exercise trial). The afternoon prior to the other fat tolerance test participants rested (control trial). Trials were performed in a counterbalanced randomized design.

For two days preceding the main trials participants were asked to refrain from physical activity other than the resistance exercise. Only gentle walking for personal transportation over short distances was permitted. Participants weighed and recorded all food and drink consumed during the $48 \mathrm{~h}$ immediately preceding their first trial and they undertook to replicate this intake during the $48 \mathrm{~h}$ prior to their second trial. Participants also refrained from alcohol during these periods. 
Anthropometry.

Height and weight were determined using standard methods. Skinfold thicknesses were measured at three sites (chest, triceps, subscapular) using calipers. Body density was calculated using a three sites formula as outlined by Jackson and Pollock and body fat percentage then estimated using the Siri equation (Jackson and Pollock, 1985).

\section{Weight lifting protocol.}

Each participant performed four sets of 10 repetitions of 11 different weight-lifting exercises at $80 \%$ of 10 repetition maximum. Four sets of each exercise were employed in order to maximise the total energy expenditure of the session and hence the likelihood of reducing postprandial lipaemia. A training intensity of $80 \%$ of 10 repetition maximum was chosen as a compromise between muscular strength and endurance. Pilot work revealed that a higher training intensity would have prevented most participants from completing four sets of each exercise and thus would have lowered the total energy expenditure. Participants were given $2 \mathrm{~min}$ in which to complete each set. On completion of the 10 repetitions participants rested for the remainder of the $2 \mathrm{~min}$. Therefore, the whole exercise session lasted $88 \mathrm{~min}$ (11 exercises $\times 4$ sets $\times 2 \mathrm{~min}$ ). The order of the exercises was uniform for all participants: dead lift, bench press, upright row, squat, shoulder press, bent-over row, lunges, barbell pullover, bicep curls, triceps press and sit ups. All sets for one exercise were completed before moving on to the next exercise. The session was structured to avoid local muscular fatigue from exercising similar muscle groups 
consecutively. It was also designed so that large muscle groups were exercised first. Standard free weights were used, including dumbbells, bent bar, an Olympic bar and a mobile bench. Water intake was permitted ad libitum throughout the resistance exercise session.

\section{Estimation of energy expenditure during weight lifting.}

Expired air samples were collected into Douglas bags (Plysu Protection Systems, Milton Keynes, U.K.) during the third set of each weight lifting exercise (pilot work revealed that there was no systematic variation in oxygen consumption values measured during the first, second, third and fourth set of each exercise). Samples were collected for the full duration of the lifting and recovery period i.e. 2 min. Oxygen consumption $\left(\mathrm{O}_{2}\right)$ and carbon dioxide production $\left(\mathrm{CO}_{2}\right)$ were determined from expired air samples using a paramagnetic oxygen analyzer and an infra-red carbon dioxide analyzer respectively (Series 1400; Servomex, Crowborough, East Sussex, U.K.). Expired air volumes were measured using a dry gas meter (Harvard Apparatus, Edenbridge, Kent, U.K.) and corrected to standard temperature and pressure (dry).

The short duration, intermittent nature of weight lifting invalidates the typical assumptions of indirect calorimetry because the respiratory exchange ratio (RER) is consistently equal to or greater than 1.0. Therefore, energy expenditure was calculated as being $5.047 \mathrm{kcal}(21.1 \mathrm{~kJ})$ per litre of oxygen (McArdle et al., 2001). This reflects the assumption that energy was derived from carbohydrate rather than 
fat oxidation and assumes no protein contribution to energy provision during the exercise. This assumption may not be entirely valid, in which case our energy expenditure estimations may be slightly on the high side. No attempt was made to quantify the energy contribution from anaerobic sources.

\section{Fat tolerance tests.}

The protocol for the fat tolerance tests is shown in Figure 1. Participants reported to the laboratory at $08.00 \mathrm{~h}$ after a 12 -h fast. A cannula was inserted into a forearm or antecubital vein and the participant rested quietly for $10 \mathrm{~min}$ before a baseline blood sample was obtained. The participant then lay quietly whilst resting metabolic rate (RMR) and RER were measured. The test meal was then consumed. This comprised whipping cream, fruit, cereal, nuts, chocolate and sugar and was given according to body mass $(1.2 \mathrm{~g}$ fat, $1.1 \mathrm{~g}$ carbohydrate, $0.2 \mathrm{~g}$ protein, $68 \mathrm{~kJ}, 0.09 \mathrm{~g}$ fiber, per $\mathrm{kg}$ body mass). Further blood samples were obtained at $0.5,0.75$ and $1 \mathrm{~h}$ after the start of the meal and then hourly for a total of $6 \mathrm{~h}$. The cannula was kept patent by flushing with nonheparinised saline $\left(9 \mathrm{~g} \cdot \mathrm{L}^{-1}\right.$, B.Braun Medical Ltd, Buckinghamshire, UK). The first $2 \mathrm{~mL}$ of blood withdrawn was always discarded to avoid dilution of the sample. Every participant consumed all of the prescribed meal.

Only water was consumed during the 6 -h postprandial observation period. Water was available ad libitum during the first trial; the volume ingested was recorded and replicated in the second trial. Participants rested (reading, working quietly, watching television) throughout each observation period and were always lying in a supine position for at least 5 min before blood samples were taken. 
FIGURE 1 NEAR HERE

\section{Energy expenditure at rest and during the postprandial period.}

Resting metabolic rate and RER were measured using a ventilated hood attached to an automated metabolic cart (GEM Europa Scientific, NutrEn Technology Ltd., Manchester, U.K.). Participants were asked not to shower on the morning of the tests and to travel to the laboratory by car. This was to ensure that they were in a rested state. On arrival at the laboratory they were comfortably positioned on a bed and RMR was measured after placement of a cannula and withdrawal of a baseline blood sample. Participants spent 15 min under the hood. The first 5 min served as a habituation and calibration period. $\mathrm{O}_{2}$ and $\mathrm{CO}_{2}$ values were calculated every 30 seconds for the remaining $10 \mathrm{~min}$. The mean values for $\mathrm{O}_{2}$ and $\mathrm{CO}_{2}$ were used to estimate the amount of fat and carbohydrate oxidized during the measurement period assuming no protein oxidation (Frayn, 1983). Postprandial metabolic rate was measured at 2.5 and 5.5 hours following food consumption using the same procedure employed to measure RMR.

\section{Analytical Methods.}

At each sampling point, blood samples were collected into pre-cooled 9-mL potassium-EDTA monovettes (Sarstedt, Leicester, UK) and were kept on ice until centrifugation. Plasma was separated within 15 min of collection, divided into aliquots, and stored at $-20^{\circ} \mathrm{C}$. Plasma samples were analysed (within six months of collection) for TAG, glucose, cholesterol, HDL cholesterol (Randox Laboratories 
Ltd. U.K.) and non-esterified fatty acids (NEFA) (Wako Chemicals GmbH, Germany) by enzymatic, colorimetric methods with the use of a centrifugal analyzer (Cobas-Bio; Roche, Basel, Switzerland). Plasma insulin concentration was determined using a solid-phase ${ }^{125}$ I radioimmunoassay available in a commercial kit (ICN Pharamaceuticals, Inc., Costa Mesa, CA). The within batch coefficients of variation for these assays were as follows: TAG 1.8\%, glucose, $1.3 \%$, cholesterol $1.0 \%$, HDL cholesterol $1.4 \%$, NEFA $0.8 \%$, insulin $5.7 \%$. To eliminate inter-assay variation, samples from both trials for each participant were always analysed in the same batch. Haemoglobin concentration and haematocrit were determined in samples collected at baseline and 6-h so that changes in plasma volume could be estimated (Dill and Costill, 1974).

\section{Data Analysis.}

Postprandial responses for TAG, NEFA, glucose and insulin were calculated using the six hour areas under the plasma concentration versus time curves using the trapezium rule. Incremental area under curve values were calculated using the same method after correcting for baseline concentrations. Insulin sensitivity was calculated as the ratio of the total area under the insulin concentration versus time curve, to the total area under the glucose concentration versus time curve (Lamarche et al., 1993). Fasting and area under the curve values were compared between trials using Student's t-tests for correlated means. Two-way ANOVA (repeated measures) was used to determine differences between trials and over time for fasting and postprandial plasma concentrations of TAG, NEFA, glucose and insulin as well as 
224 for RER, energy expenditure, carbohydrate and fat oxidation. When there was a

225 main effect of time, differences between individual means were assessed using

226 Student's t-tests with a Bonferroni adjustment. Relationships between variables were

227 evaluated using Pearson's product-moment correlation coefficient. A 5\% level of

228 significance was adopted throughout, and data are expressed as means $\pm \mathrm{SE}$.

229 


\section{RESULTS}

231

232

Responses during weight lifting.

The mean weight lifted during the 88 minute resistance exercise session was 14,214 $\pm 613 \mathrm{~kg}$. Mean $\mathrm{O}_{2}$ was $1.22 \pm 0.03 \mathrm{~L} \cdot \mathrm{min}^{-1}$ with a mean RER value of $1.05 \pm$ 0.02 over this period. The gross energy expenditure from the exercise was estimated to be $2.3 \pm 0.3 \mathrm{MJ}$ and the net (gross minus resting) energy expenditure was estimated at $1.8 \pm 0.06 \mathrm{MJ}$.

Plasma concentrations in the fasted state.

Plasma concentrations in the fasted state are shown in Table 2. No significant differences were seen in fasting plasma TAG, NEFA, total cholesterol, glucose or insulin concentrations between control and exercise trials, although plasma insulin showed a tendency to be higher in the control trial $(P<0.10)$. Plasma HDL-C concentrations were lower in the exercise trial than the control trial $(P<0.05)$.

\section{TABLE 2 NEAR HERE}

Postprandial plasma responses to the fat tolerance tests.

Changes in plasma volume over the period of observation were small and did not differ significantly between control $(0.2 \pm 2.7 \%)$ and exercise $(-2.5 \pm 2.0 \%)$ trials. No adjustments were made, therefore, to measured concentrations of plasma constituents. 
Total and incremental plasma TAG concentrations following the fat tolerance tests are shown in Figure 2, with summary measures (areas under the curve) of these responses in Table 3. No difference was seen in either the total or the incremental area under the curve values between the control and exercise conditions. No difference was observed in the peak TAG concentration (control $2.15 \pm 0.26$ $\mathrm{mmol} \cdot \mathrm{L}^{-1}$, exercise $2.16 \pm 0.26 \mathrm{mmol} \cdot \mathrm{L}^{-1}$ ) or time-to-peak TAG concentration (control $3.45 \pm 0.43 \mathrm{~h}$, exercise $3.45 \pm 0.49 \mathrm{~h}$ ). Positive relationships were seen in both trials between the total area under the curve and the fasting TAG concentrations (control $r=0.95, P<0.01$; exercise $r=0.93, P<0.01$ ).

\section{FIGURE 2 NEAR HERE}

\section{TABLE 3 NEAR HERE}

Postprandial plasma NEFA, glucose and insulin responses are shown in Figure 3 and area under the curve values are presented in Table 3 . There were no significant differences in area under the curve values between trials for any of these variables. Neither were there any significant differences between trials for peak insulin concentration (control $119.3 \pm 15.4 \mu \mathrm{U} \cdot \mathrm{mL}^{-1}$, exercise $109.8 \pm 29.1 \mu \mathrm{U} \cdot \mathrm{mL}^{-1}$ ), timeto-peak insulin concentration (control $0.64 \pm 0.05 \mathrm{~h}$, exercise $0.70 \pm 0.07 \mathrm{~h}$ ) or insulin sensitivity (control $9.42 \pm 1.18$, exercise $8.59 \pm 1.45$ ). 
Substrate utilization and energy expenditure.

The test meal provided $104.0 \pm 3.3 \mathrm{~g}$ fat, $94.3 \pm 3.0 \mathrm{~g}$ carbohydrate, $16.2 \pm 0.5 \mathrm{~g}$ protein and $5.68 \pm 0.2 \mathrm{MJ}$ energy, $69 \%$ of which was derived from fat. The time taken to consume the test meal did not differ significantly between the two trials (control $15.8 \pm 1.6 \mathrm{~min}$, exercise $14.1 \pm 1.5 \mathrm{~min}$ ).

Fasting and postprandial values for RER, energy expenditure, carbohydrate and fat oxidation are presented in Table 4. No interaction effects (trial $\mathrm{x}$ time) were found for any of these variables. A main effect of trial was found for RER indicating lower values in the exercise compared to the control trial. A main effect of time was seen for energy expenditure indicating a higher rate of expenditure at 2.5 hours compared to fasting and 5.5 hour values. A main effect of time was also observed for the rate of fat oxidation which was elevated at 2.5 and 5.5 hours compared to fasting values. 


\section{DISCUSSION}

The main finding in the present study is that a single session of resistance exercise, performed 16 hours prior to an oral fat tolerance test, did not influence postprandial lipaemia. Whatever way the postprandial TAG response was compared (peak TAG concentration, time to peak TAG concentration, total area under the TAG concentration versus time curve, incremental area under the TAG concentration versus time curve) there was no significant difference between trials. This is in contrast to the findings from studies of aerobic exercise, most of which demonstrate a lowering of postprandial lipaemia the day after a single session of exercise (Aldred et al., 1994; Tsetsonis and Hardman, 1996a; Tsetsonis and Hardman, 1996b; Tsetsonis et al., 1997; Malkova et al., 2000; Herd et al., 2001; Gill et al., 2002; Gill et al., 2003). The findings of the present study are also in conflict with those of Petitt and colleagues (2003) who found a significant reduction in postprandial lipaemia 16 hours after a bout of resistance exercise.

A possible explanation for the failure of resistance exercise to influence postprandial lipaemia in the present study is insufficient energy expenditure. The estimated gross energy expended during the resistance exercise in our study was $2.3 \mathrm{MJ}$ (range = 2.0-2.6 MJ). In previous studies examining the acute effects of aerobic exercise on postprandial lipaemia, the average gross energy expenditure found to attenuate the lipemic response has ranged from 1.5 to 7.2 MJ (Petitt and Cureton, 2003). The energy expenditure elicited in the present study is at the lower end of this spectrum. Although Tsetsonis and colleagues (1997) found an expenditure of 2.3 MJ to be 
sufficient to attenuate postprandial lipaemia in untrained participants, their participants were females who were on average 20 years older (43.8 y) and $20 \mathrm{~kg}$ lighter $(62.2 \mathrm{~kg})$ than the males in the present study. Thus, relative to body mass, 2.3 MJ represents a greater level of expenditure for the participants of Tsetsonis et al. (1997) than for the participants in the present study.

Another possible explanation for the conflict between the findings of the present study and those concerning studies of aerobic exercise relates to the enzyme LPL. This enzyme is located on the capillary endothelium and is particularly abundant in the heart, adipose tissue and skeletal muscle (Seip and Semenkovich, 1998). LPL is responsible for hydrolyzing TAG rich lipoproteins and directing the liberated fatty acids into the surrounding tissues. Several studies have demonstrated increases in skeletal muscle LPL activity following a single bout of prolonged aerobic exercise (Lithell et al., 1979; Lithell et al., 1981) and this is thought to be the major mechanism by which such exercise reduces postprandial lipaemia.

To our knowledge no studies have examined the effects of resistance exercise on LPL activity but an acute bout of knee extension exercise appears to have a less dramatic effect on LPL activity than the changes found following aerobic exercise (Kiens and Lithell, 1989; Kiens et al., 1989). This is possibly because kneeextension exercise, unlike whole-body exercise, evokes little catecholamine response and catecholamines are one of the factors leading to activation of LPL (Newsholme and Leech, 1994). Thus, it may be that the small muscle mass utilized in some of the 
exercises in the present study had minimal influence on catecholamines and therefore LPL activity. However, some of the exercises employed in our study did involve major muscle groups. Moreover, the plasma catecholamine response has been elevated in other studies examining acute hormonal responses to heavy resistance exercise in both trained and untrained men (Kraemer et al., 1993; Kraemer et al., 1999). It seems unlikely, therefore, that a reduced catecholamine response would, on its own, explain our findings.

Neither of the previous explanations (insufficient energy expenditure, insufficient activation of LPL) can account for the differences between our findings and those of the one previous study which has examined resistance exercise and postprandial lipaemia. Petitt and colleagues (2003) found a 14\% reduction in postprandial lipaemia following a bout of resistance exercise involving 3 sets of 10 repetitions of 10 exercises performed at 10 repetition maximum. In the present study a greater volume of exercise was completed (4 sets of 10 repetitions of 11 exercises) although the intensity was lower ( $80 \%$ of 10 repetition maximum). The length of the resistance exercise session was identical in the two studies $(88 \mathrm{~min})$ but estimated energy expenditure was $35 \%$ higher in our study (2.3 versus $1.7 \mathrm{MJ})$. This was probably due to a greater volume of work being completed in our study although inconsistency between the methods used to estimate energy expenditure may also have contributed to the difference (a precise description of how energy expenditure was estimated is not given by Petitt et al. 2003). The gap between the resistance exercise and the test meal was also identical between studies (16 hours) and the test 
meals employed in each study provided very similar energy and macronutrient content. Thus, none of these factors would seem to explain the discrepancy between studies.

One factor which may explain the differences in findings between these studies is the nature of the participants involved. The study of Petitt and colleagues (2003) involved males $(n=10)$ and females $(n=4)$ who had six-years experience of weight lifting. In contrast, none of the participants in the present study were regularly involved in resistance training. Thus, it is possible that the physiological stress associated with this unfamiliar form of exercise may have caused skeletal muscle damage in our participants which may not have occurred in the relatively welltrained participants of Petitt and colleagues (2003). Skeletal muscle damage may elevate concentrations of the cytokine tumor necrosis factor- $\alpha$ which has been associated with transient insulin resistance due to a down regulation of insulinreceptor-signalling in adipocytes, hepatocytes and skeletal muscle (Kirwan and Jing, 2002). This may have impaired the uptake of TAG into adipose tissue/skeletal muscle (via a reduced stimulation of LPL). It may also have reduced the efficiency of insulin in suppressing fat mobilisation from adipose tissue and the liver. However, we do not have firm evidence to support these ideas.

It is feasible that a reduction in postprandial lipaemia is dependent on the relative substrate contribution to energy metabolism during exercise. If this were the case and if fat was not a major source of fuel during resistance exercise then perhaps 
there would be limited impact on postprandial lipaemia. However, there is evidence to show that fat does provide a significant source of fuel during resistance exercise since muscle biopsy samples taken from the vastus lateralis muscles of bodybuilders immediately after a 30 minute bout of heavy resistance exercise indicated a $30 \%$ reduction in intramuscular TAG in comparison to pre-exercise values (EssenGustavsson and Tesch, 1990). Moreover, Malkova and colleagues (1999) found no difference in the postprandial TAG response following 90 min of treadmill running when fat metabolism was inhibited by acipimox during running on one occasion. They concluded that the mechanisms by which prior exercise attenuates postprandial lipaemia are not influenced by the relative contributions of fat and carbohydrate to energy metabolism during exercise.

Resting fat oxidation is usually increased the morning after an aerobic exercise bout and fasting TAG concentration is often reduced (Tsetsonis et al., 1997; Tsetsonis and Hardman, 1996b). In their study of resistance exercise and postprandial lipaemia Petitt and colleagues (2003) also observed that resting fat oxidation was higher and fasting TAG concentration lower, the morning after exercise compared to the morning of the control trial. These findings may reflect an acute state of negative energy balance that requires greater mobilization and oxidation of fatty acids (Melby et al., 1993). Such changes may be required prior to any lowering of postprandial lipaemia. In the present study fasting TAG concentrations were not reduced the morning after resistance exercise and fat oxidation was not enhanced. This is consistent with the findings of another recent study of resistance exercise (Melanson 
et al., 2002) and may be an explanation for the lack of change in postprandial lipaemia. However, a reduction in postprandial lipaemia has been observed in the absence of changes to fasting TAG concentration and resting fat oxidation (Herd et al., 2001), so this is unlikely to fully explain the lack of change in our study.

\section{One finding which we are unable to explain is the significantly lower HDL} cholesterol concentration observed on the morning after the resistance exercise bout compared with the control trial. Previous studies of acute exercise and postprandial lipaemia have not detected any difference in fasting HDL cholesterol concentrations between exercise and control trials. Moreover, most evidence indicates that resistance exercise does not influence fasting HDL cholesterol concentration (Durstine and Haskell, 1994).

In conclusion, our findings indicate that a single session of resistance exercise does not influence postprandial lipaemia. These findings conflict with those of the only other study which we are aware of that has examined the relationship between resistance exercise and postprandial lipaemia (Petitt et al., 2003). Further research is required to clarify this relationship, given the emphasis on resistance exercise in physical activity recommendations (U.S. Department of Health and Human Services, 1996; American College of Sports Medicine, 1998). In particular, research is required to evaluate whether or not muscle damage, such as that which can occur during resistance exercise, influences postprandial lipaemia. 


\section{REFERENCES}

Aldred, H. E., Perry, I. C. and Hardman, A. E. (1994). The effect of a single bout of brisk walking on postprandial lipemia in normolipidemic young adults. Metabolism, 43, 836-841.

American College of Sports Medicine (1998) The recommended quantity and quality of exercise for developing and maintaining cardiorespiratory and muscular fitness, and flexibility in healthy adults. Medicine and Science in Sports and Exercise, 30, 975-991.

Cohn, J. S. (1998). Postprandial lipemia: emerging evidence for atherogenicity of remnant lipoproteins. Canadian Journal of Cardiology, 14 (Suppl. B), 18B-27B.

Dill, D. B. and Costill, D. L. (1974). Calculation of percentage changes in volumes of blood, plasma, and red cells in dehydration. Journal of Applied Physiology, 37, 247-248.

Durstine, J. L. and Haskell, W. L. (1994). Effects of exercise training on plasma lipids and lipoproteins. Exercise and Sport Sciences Reviews, 22, 477-521.

Essen-Gustavsson, B. and Tesch, P. A. (1990). Glycogen and triacylglycerol utilization in relation to muscle metabolic characteristics in men performing heavy- 
resistance exercise. European Journal of Applied Physiology and Occupational Physiology, 61, 5-10.

Frayn, K. N. (1983). Calculation of substrate oxidation rates in vivo from gaseous exchange. Journal of Applied Physiology, 55, 628-634.

Gill, J. M. R., Herd, S. L. and Hardman, A. E. (2002). Moderate exercise and postprandial metabolism: issues of dose-response. Journal of Sports Sciences, 20, 961967.

Gill, J. M. R., Mees, G. P., Frayn, K. N. and Hardman, A. E. (2001). Moderate exercise, postprandial lipaemia and triacylglycerol clearance. European Journal of Clinical Investigation, 31, 201-207.

Gill, J. M. R., Herd, S. L., Vora, V. and Hardman, A. E. (2003). Effects of a brisk walk on lipoprotein lipase activity and plasma triglyceride concentrations in the fasted and postprandial states. European Journal of Applied Physiology, 89, 184190.

Hardman, A. E., Lawrence, J. E. M. and Herd, S. L. (1998). Postprandial lipemia in endurance-trained people during a short interruption to training. Journal of Applied Physiology, 84, 1895-1901. 
Herd, S. L., Hardman, A. E., Boobis, L. H. and Cairns, C. J. (1998). The effect of 13 weeks of running training followed by $9 \mathrm{~d}$ of detraining on postprandial lipaemia. British Journal of Nutrition, 80, 57-66.

Herd, S. L., Kiens, B., Boobis, L. H. and Hardman, A. E. (2001). Moderate exercise, postprandial lipemia, and skeletal muscle lipoprotein lipase activity. Metabolism, 50, 756-762.

Jackson, A. S. and Pollock, M. L. (1985). Practical assessment of body composition. Physician and Sports Medicine., 13, 76-90.

Karpe, F. and Hamsten, A. (1995). Postprandial lipoprotein metabolism and atherosclerosis. Current Opinion in Lipidology, 6, 123-129.

Kiens, B. and Lithell, H. (1989). Lipoprotein metabolism influenced by traininginduced changes in human skeletal muscle. Journal of Clinical Investigation, 83, $558-564$.

Kiens, B., Lithell, H., Mikines, K. J. and Richter, E. (1989). Effects of insulin and exercise on muscle lipoprotein lipase activity in man and its relation to insulin action. Journal of Clinical Investigation, 84, 1124-1129. 
Kirwan, J. P. and Jing, M. (2002). Modulation of insulin signaling in human skeletal muscle in response to exercise. Exercise and Sport Sciences Reviews, 30, 85-90.

Kraemer, W. J., Dziados, J. E., Marchitelli, L. J., Gordon, S. E., Harman, E. A., Mello, R., Fleck, S. J., Frykman, P. N. and Triplett, N. T. (1993). Effects of different heavy-resistance exercise protocols on plasma ß-endorphin concentrations. Journal of Applied Physiology, 74, 450-459.

Kraemer, W. J., Fleck, S. J., Maresh, C. M., Ratamess, N. A., Gordon, S. E., Goetz, K. L., Harman, E. A., Frykman, P. N., Volek, J. S., Mazzetti, S. A., Fry, A. C., Marchitelli, L. J. and Patton, J. F. (1999). Acute hormonal responses to a single bout of heavy resistance exercise in trained power lifters and untrained men. Canadian Journal of Applied Physiology, 24, 524-537.

Lamarche, B., Després, J. P., Moorjani, S., Nadeau, A., Lupien, P. J., Tremblay, A., Thériault, G. and Bouchard, C. (1993). Evidence for the role of insulin in the regulation of abdominal and adipose tissue lipoprotein lipase response to exercise training in obese women. International Journal of Obesity, 17, 255-261.

Lithell, H., Örlander, J., Schéle, R., Sjödin, B. and Karlsson, J. (1979). Changes in lipoprotein-lipase activity and lipid stores in human skeletal muscle with prolonged heavy exercise. Acta Physiologica Scandinavia, 107, 257-261. 
Lithell, H., Cedermark, M., Fröberg, J., Tesch, P. and Karlsson, J. (1981). Increase of lipoprotein-lipase activity in skeletal muscle during heavy exercise. Relation to epinephrine excretion. Metabolism, 30, 1130-1134.

Malkova, D., Hardman, A. E., Bowness, R. J. and Macdonald, I. A. (1999). The reduction in postprandial lipemia after exercise is independent of the relative contributions of fat and carbohydrate to energy metabolism during exercise. Metabolism, 48, 245-251.

Malkova, D., Evans, R. D., Frayn, K. N., Humphreys, S. M., Jones, P. R. M. and Hardman, A. E. (2000). Prior exercise and postprandial substrate extraction across the human leg. American Journal of Physiology, Endocrinology and Metabolism, 279, E1020-E1028.

McArdle, W.D., Katch, F.I. and Katch, V.L. (2001) Exercise Physiology: Energy, Nutrition, and Human Performance. Lippincott Williams and Wilkins. Philadelphia.

Melanson, E. L., Sharp, T. A., Seagle, H. M., Donahoo, W. T., Grunwald, G. K., Peters, J. C., Hamilton, J. T. and Hill, J. O. (2002). Resistance and aerobic exercise have similar effects on 24-h nutrient oxidation. Medicine and Science in Sports and Exercise, 34, 1793-1800. 
540 Melby, C., Scholl, C., Edwards, G. and Bullough, R. (1993). Effect of acute

541 resistance exercise on postexercise energy expenditure and resting metabolic rate.

542 Journal of Applied Physiology, 75, 1847-1853.

543

Newsholme, E.A. and Leech, A.R. (1994) Biochemistry for the Medical Sciences.

Wiley. Chichester.

546

Patsch, J. R., Miesenböck, G., Hopferwieser, T., Mühlberger, V., Knapp, E., Dunn,

J. K., Gotto, A. M. and Patsch, W. (1992). Relation of triglyceride metabolism and coronary artery disease. Studies in the postprandial state. Arteriosclerosis and Thrombosis, 12, 1336-1345.

551

Petitt, D. S. and Cureton, K. J. (2003). Effects of prior exercise on postprandial lipemia: a quantitative review. Metabolism, 52, 418-424.

554

Petitt, D. S., Arngrímsson, S. Á. and Cureton, K. J. (2003). Effect of resistance exercise on postprandial lipemia. Journal of Applied Physiology, 94, 694-700.

Seip, R. L. and Semenkovich, C. F. (1998). Skeletal muscle lipoprotein lipase: molecular regulation and physiological effects in relation to exercise. Exercise and Sports Sciences Reviews, 26, 191-218. 
562 Tsetsonis, N. V. and Hardman, A. E. (1996a). Effects of low and moderate intensity 563 treadmill walking on postprandial lipaemia in healthy young adults. European 564 Journal of Applied Physiology, 73, 419-426.

565

Tsetsonis, N. V. and Hardman, A. E. (1996b). Reduction in postprandial lipemia 567 after walking: influence of exercise intensity. Medicine and Science in Sports and 568 Exercise, 28, 1235-1242.

569 570 middle-aged women. American Journal of Clinical Nutrition, 65, 525-533. Health: A Report of the Surgeon General. Atlanta, G.A. Department of Health and Human Services, Centers for Disease Control and Prevention, National Centre for Chronic Disease Prevention and Health Promotion. 
579

580

581

582

583

584

Figure Legends

Figure 1: Study protocol.

Figure 2: Total (a) and incremental (b) plasma triacylglycerol (TAG) concentrations in the fasted state $(0 \mathrm{~h})$ and for $6 \mathrm{~h}$ following consumption of a high-fat mixed meal in the control and resistance exercise trials. Values are mean $\pm \mathrm{SE}, n=11$.

Figure 3: Plasma NEFA (a), glucose (b) and insulin (c) concentrations in the fasted state $(0 \mathrm{~h})$ and for $6 \mathrm{~h}$ following consumption of a high-fat mixed meal in the control and resistance exercise trials. Values are mean \pm SE, $n=11$. 
Table 1. Physical characteristics of the participants.

Age (y)

$23.45 \pm 1.39$

Height (m)

$1.80 \pm 0.02$

Body Mass (kg)

$84.26 \pm 2.73$

BMI $\left(\mathrm{kg} \cdot \mathrm{m}^{-2}\right)$

$25.87 \pm 0.71$

Body fat (\%)

$14.4 \pm 1.6$

Values are mean $\pm \mathrm{SE}, n=11$ 
Table 2. Plasma concentrations of lipids, lipoproteins, glucose and insulin in the fasted state (prior to consumption of a test meal) in the control and resistance exercise trials.

\begin{tabular}{lccc}
\hline & Control & Exercise & $P$ \\
\hline Plasma TAG $\left(\mathrm{mmol} \cdot \mathrm{L}^{-1}\right)$ & $1.03 \pm 0.13$ & $0.94 \pm 0.09$ & 0.34 \\
Total cholesterol $\left(\mathrm{mmol} \cdot \mathrm{L}^{-1}\right)$ & $4.50 \pm 0.24$ & $4.18 \pm 0.31$ & 0.21 \\
HDL cholesterol $\left(\mathrm{mmol} \cdot \mathrm{L}^{-1}\right)$ & $1.16 \pm 0.10$ & $1.02 \pm 0.08$ & 0.01 \\
NEFA $\left(\mathrm{mmol} \cdot \mathrm{L}^{-1}\right)$ & $0.51 \pm 0.05$ & $0.48 \pm 0.05$ & 0.57 \\
Glucose $\left(\mathrm{mmol} \cdot \mathrm{L}^{-1}\right)$ & $5.11 \pm 0.27$ & $4.86 \pm 0.44$ & 0.46 \\
Insulin $\left(\mu \mathrm{U} \cdot \mathrm{mL} \mathrm{L}^{-1}\right)$ & $29.37 \pm 2.04$ & $24.24 \pm 3.23$ & 0.08 \\
\hline
\end{tabular}

Values are mean \pm SE, $n=11$. 
Table 3. Six-hour areas under the plasma concentration versus time curves after consumption of a high-fat mixed meal in control and resistance exercise trials.

Control Exercise $\quad P$

\begin{tabular}{lccc}
\hline Total TAG $\left(\mathrm{mmol} \cdot \mathrm{L}^{-1} \cdot 6 \mathrm{~h}\right)$ & $9.84 \pm 1.40$ & $9.38 \pm 1.12$ & 0.47 \\
Incremental TAG $\left(\mathrm{mmol} \cdot \mathrm{L}^{-1} \cdot 6 \mathrm{~h}\right)$ & $3.66 \pm 0.67$ & $3.81 \pm 0.64$ & 0.63 \\
NEFA $\left(\mathrm{mmol} \cdot \mathrm{L}^{-1} \cdot 6 \mathrm{~h}\right)$ & $2.75 \pm 0.20$ & $2.95 \pm 0.20$ & 0.32 \\
Glucose $\left(\mathrm{mmol} \cdot \mathrm{L}^{-1} \cdot 6 \mathrm{~h}\right)$ & $30.21 \pm 0.92$ & $28.93 \pm 0.83$ & 0.30 \\
Insulin $\left(\mu \mathrm{U} \cdot \mathrm{mL}^{-1} \cdot 6 \mathrm{~h}\right)$ & $295.4 \pm 39.1$ & $273.8 \pm 52.4$ & 0.36
\end{tabular}

Values are mean \pm SE, $n=11$ 
Table 4. Substrate utilization and energy expenditure in the fasted and postprandial states.

Fasting 2.5 Hours 5.5 Hours Mean

RER

$\begin{array}{lcccc}\text { Control } & 0.82 \pm 0.02 & 0.82 \pm 0.02 & 0.79 \pm 0.02 & 0.81 \pm 0.01^{*} \\ \text { Exercise } & 0.81 \pm 0.02 & 0.78 \pm 0.01 & 0.78 \pm 0.01 & 0.79 \pm 0.01 \\ \text { Mean } & 0.82 \pm 0.01 & 0.80 \pm 0.01 & 0.79 \pm 0.01 & \end{array}$

Energy expenditure $\left(\mathrm{kJ} \cdot \mathrm{h}^{-1}\right)$

Control

$338 \pm 23 \quad 371 \pm 23 \quad 345 \pm 19 \quad 351 \pm 12$

Exercise

$331 \pm 9 \quad 365 \pm 19 \quad 345 \pm 16 \quad 346 \pm 9$

Mean

$334 \pm 12 \quad 368 \pm 15^{\dagger} \quad 344 \pm 12^{\ddagger}$

Carbohydrate oxidation $\left(\mathrm{g} \cdot \mathrm{h}^{-1}\right)$

$\begin{array}{lllll}\text { Control } & 9.01 \pm 1.46 & 9.94 \pm 1.79 & 6.80 \pm 1.41 & 8.58 \pm 0.90 \\ \text { Exercise } & 7.60 \pm 1.17 & 6.01 \pm 1.09 & 5.62 \pm 0.94 & 6.45 \pm 0.62 \\ \text { Mean } & 8.31 \pm 0.92 & 8.07 \pm 1.12 & 6.24 \pm 0.85 & \end{array}$

Fat oxidation $\left(\mathrm{g} \cdot \mathrm{h}^{-1}\right)$

Control

$4.71 \pm 0.49$

$5.15 \pm 0.39$

$5.86 \pm 0.64$

$5.24 \pm 0.30$

Exercise

$5.16 \pm 0.50$

$6.73 \pm 0.51$

$6.37 \pm 0.39$

$6.06 \pm 0.29$

Mean

$4.93 \pm 0.34 \quad 5.90 \pm 0.36^{\dagger}$

$6.11 \pm 0.38^{\dagger}$

Values are mean \pm SE, $n=11$

*Main effect of trial by ANOVA $P<0.05$

${ }^{\dagger}$ Significantly different from fasting $P<0.05$

${ }^{\ddagger}$ Significantly different from 2.5 hours $P<0.05$ 
Day 1

Day 2

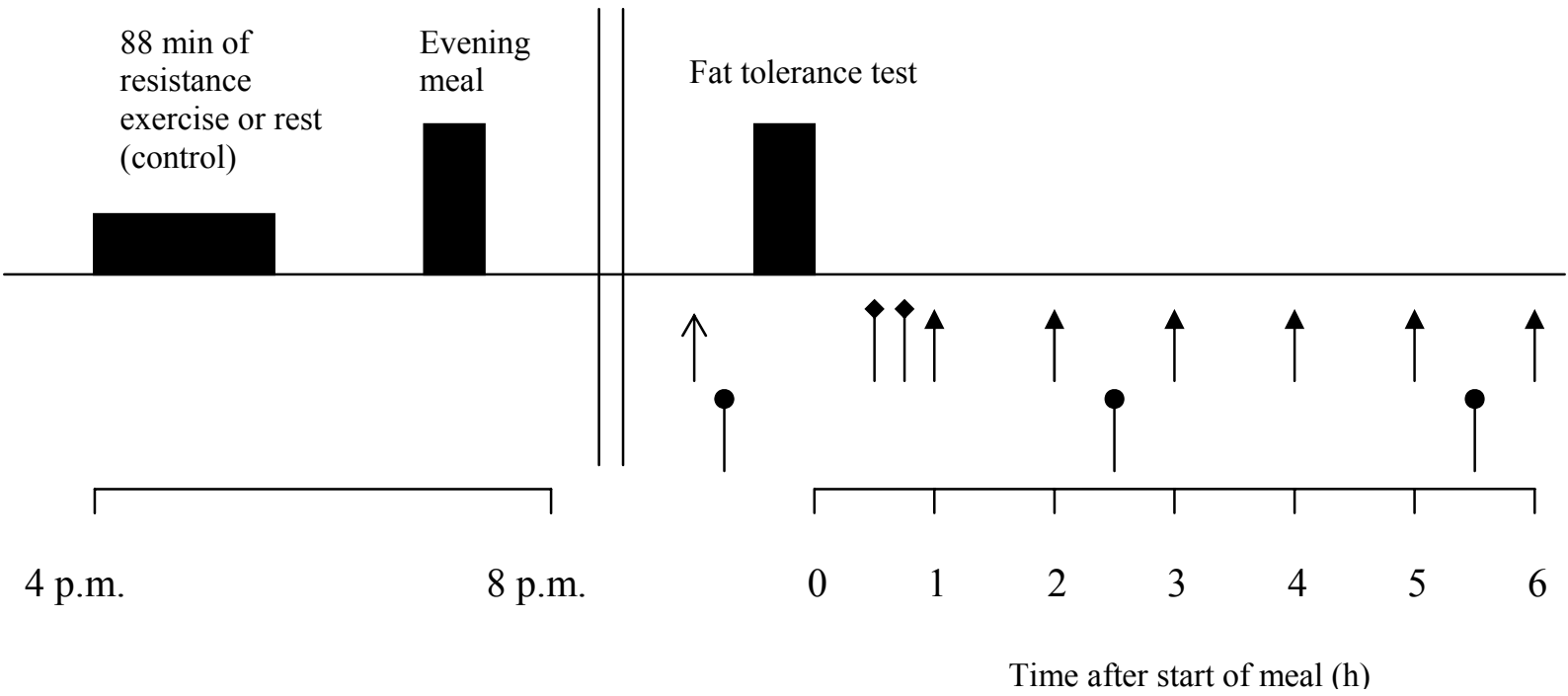

Baseline blood sample (TAG, NEFA, glucose, insulin, cholesterol, HDL cholesterol)

Blood sample (glucose, insulin)

Blood sample (TAG, NEFA, glucose, insulin)

Ventilated hood measurements 

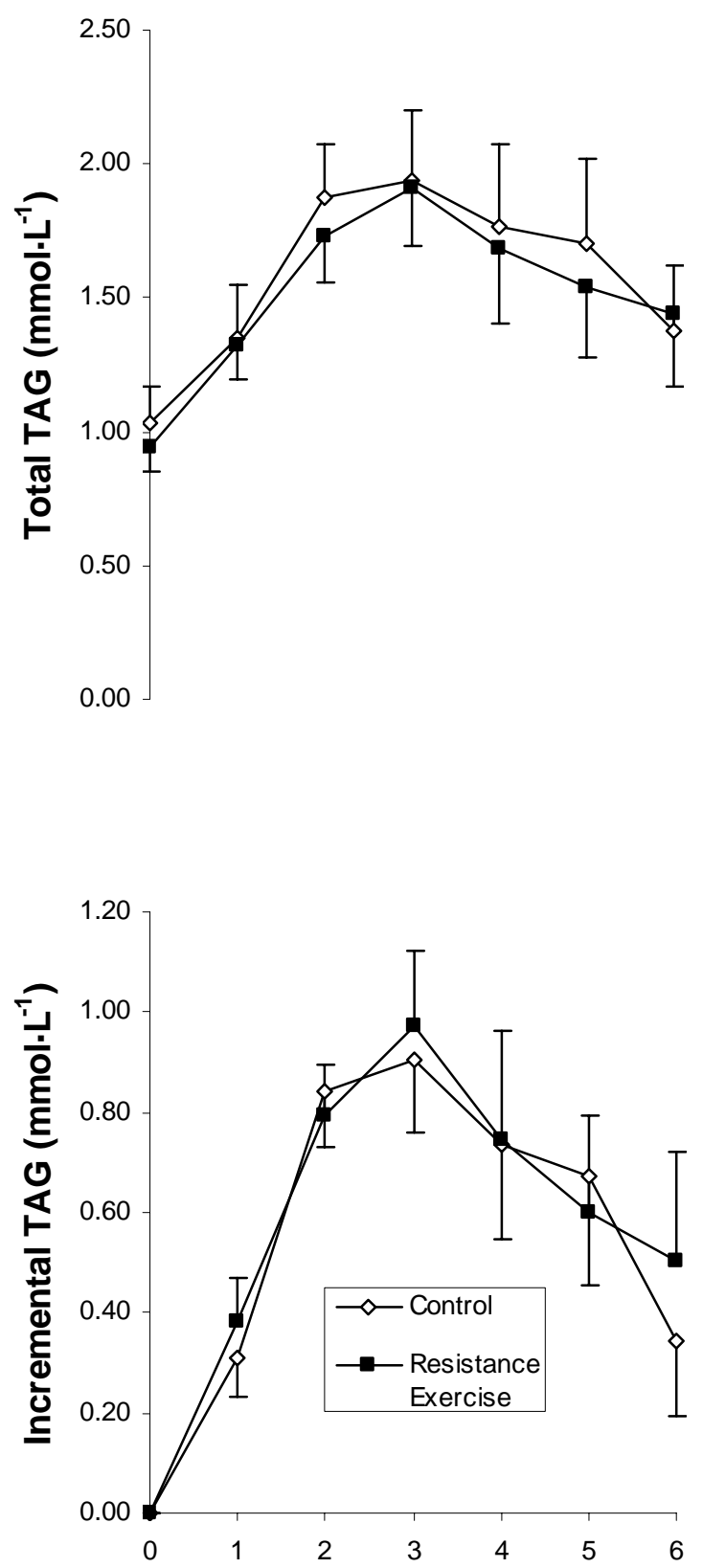

Time (h) 

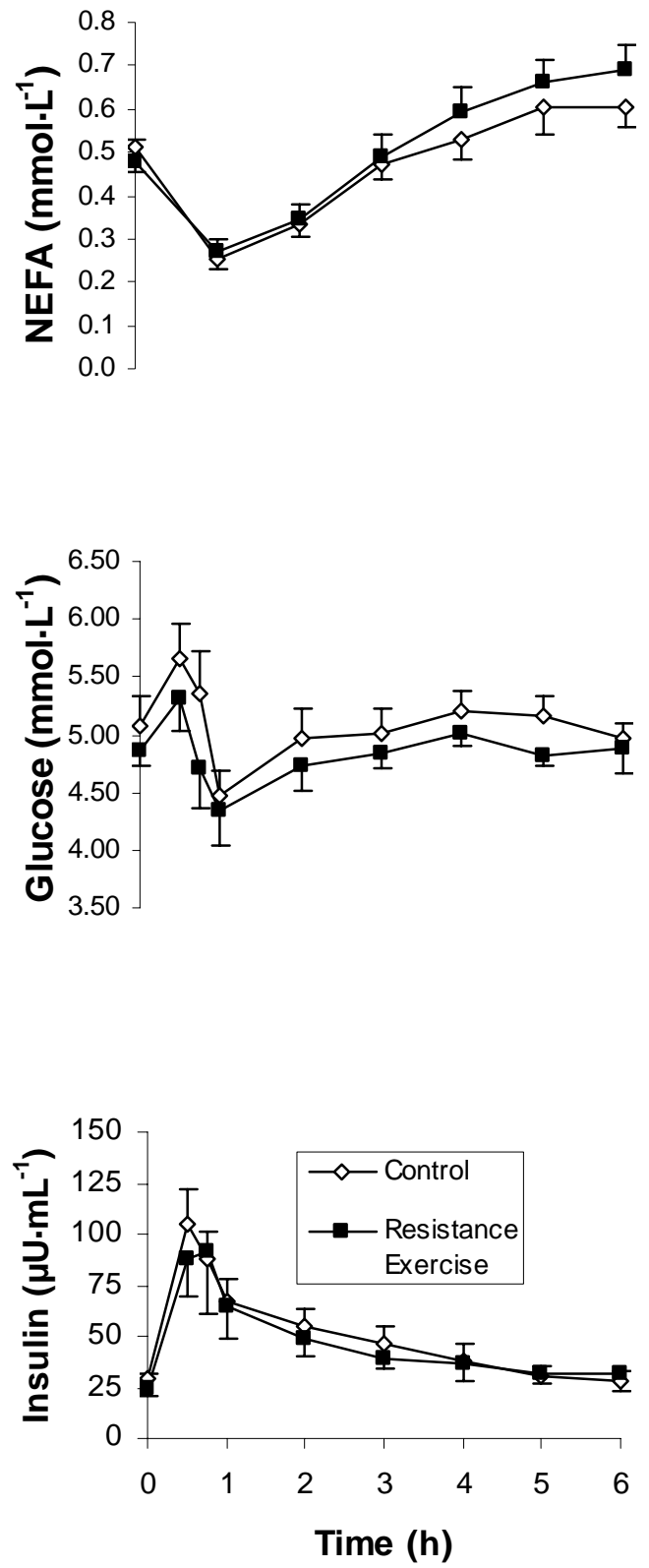